\title{
Intestinal crypt cell apoptosis in murine acute graft versus host disease is mediated by tumour necrosis factor $\alpha$ and not by the FasL-Fas interaction: effect of pentoxifylline on the development of mucosal atrophy
}

\author{
E Stüber, A Büschenfeld, A von Freier, T Arendt, U R Fölsch
}

\begin{abstract}
Background-Murine $T$ cell mediated acute semiallogeneic graft versus host disease (GVHD) is characterised by lymphocytic infiltrates, crypt hyperplasia, and villous atrophy. It has been shown that programmed cell death (apoptosis) of the crypt epithelium takes place during the intestinal manifestation of acute GVHD. Aims-To investigate which of the two most investigated inductors of apoptosis (Fas ligand (FasL) and tumour necrosis factor $\alpha(T N F-\alpha)$ ) is responsible for the induction of apoptosis in this animal model.
\end{abstract}

Methods-Animals undergoing acute semiallogeneic $\mathrm{GvH}$ reaction were treated with neutralising anti-TNF- $\alpha$, two different anti-FasL antibodies, or pentoxifylline.

Results-Anti-TNF- $\alpha$ application inhibited the appearance of apoptotic cells in the intestinal mucosa, whereas anti-FasL antibodies had no influence on mucosal apoptosis. In addition, the transfer of FasL deficient (gld) donor lymphocytes still induced crypt cell apoptosis, villous atrophy, and crypt hyperplasia. Furthermore, when the animals were treated with pentoxifylline, a known inhibitor of TNF- $\alpha$ secretion in vitro and in vivo, there was significant normalisation of the intestinal morphology accompanied by inhibition of epithelial apoptosis.

Conclusions-The FasL-Fas interaction is not involved in the induction of apoptosis during acute GVHD. However, neutralisation of TNF- $\alpha$ by an antibody or by pentoxifylline inhibits the occurrence of apoptosis and of mucosal atrophy in this animal model. These results have implications for the treatment of immunologically mediated human atrophic gut diseases-for example, diet refractory cases of coeliac disease.

(Gut 1999;45:229-235)

Keywords: graft versus host disease; tumour necrosis factor; Fas ligand; pentoxifylline; apoptosis; crypt cell

Dr Eckhard Stüber,

Medizinische Uni.-Klinik, Klinik für Allg. Innere

Medizin, Schittenhelmstraße

12, 24105 Kiel, Germany.

Accepted for publication 2 February 1999 Apoptosis has been shown to be critically important for developmental processes, ${ }^{1}$ for control of neoplastic growth, ${ }^{2}$ and for homoeo- stasis of the immune system. ${ }^{3}$ The interaction of $\mathrm{T}$ cells with epithelial cells is of specific interest in this respect. In a previous study we showed that crypt epithelial cells die due to apoptosis during the manifestation of mucosal atrophy in the murine model of $\mathrm{T}$ cell mediated acute graft versus host disease (GVHD). ${ }^{4}$

Apoptosis has been shown to be induced by multiple soluble and membrane bound factors in numerous experimental systems. ${ }^{5}$ However, tumour necrosis factor (TNF) $\alpha$ and the Fas ligand (FasL)-Fas interaction are the two most investigated mediators of apoptosis. Furthermore, they have also been suggested to be effector mechanisms in the injury of the target organs (liver, skin, gastrointestinal tract) during an acute $\mathrm{GvH}$ reaction. Mowat and colleagues ${ }^{6}$ showed that application of recombinant $\mathrm{TNF}-\alpha$ alone can induce typical gut injury - consisting of crypt hyperplasia and villous atrophy - and Piguet et al showed that neutralisation of TNF- $\alpha$ in murine acute GVHD leads to reduced target organ damage. ${ }^{7}$ Whether this damage is induced by direct TNF- $\alpha$ mediated apoptosis and which cell type is mainly affected, is not known. On the other hand, there are few data concerning the relevance of the Fas-FasL interaction in intestinal apoptosis during acute GvH. Recently, Sakai et al published a study in which they showed the capacity of freshly prepared intraepithelial lymphocytes of $\mathrm{GvH}$ animals to cause cytotoxicity in vitro via a FasL mediated mechanism. ${ }^{8}$ However, the in vivo relevance of the FasL-Fas interaction was not investigated in these studies.

Therefore, the different impacts of the blockade of the FasL-Fas interaction on the one hand versus neutralisation of TNF- $\alpha$ on the other, on the occurrence of intestinal crypt cell apoptosis in murine acute GVHD were investigated. As a second step, we studied the effect of pentoxifylline- a known inhibitor of TNF- $\alpha$ liberation in vitro and in vivo ${ }^{9}$ - on the occurrence of apoptosis in the gut and on the development of crypt hyperplasia and villous atrophy.

Abbreviations used in this paper: FasL, Fas ligand;
GVHD, graft versus host disease; TNF, tumour necrosis factor; IFN, interferon; IL, interleukin; GvH, graft versus host. 


\section{Materials and methods}

ANIMALS, CELL PREPARATIONS, AND INDUCTION OF ACUTE SEMIALLOGENEIC GvH DISEASE

Mouse strains C57/BL6, DBA2, and the F1 generation of these two strains (B6D2F1) were raised and kept under standard conditions in the animal facility of the University Hospital of Kiel, Germany.

To induce semiallogeneic GVHD a slightly modified procedure as described by GuyGrand and Vassalli $^{10}$ was performed. To prepare donor lymphocytes, spleen and mesenteric lymph nodes of C57/BL6 mice were removed and pressed through a cell filter (40 $\mu \mathrm{m}$ pore size). Red blood cells were subsequently lysed by a hypotonic lysing buffer (ACK buffer, Boehringer Ingelheim, Germany). The resulting lymphocytes $\left(80 \times 10^{6}\right.$ cells/animal) were transferred to 8-14 week old irradiated (7.5 Gy) B6D2F1 mice of the same sex by intraperitoneal injection. Three or six days after the induction of semiallogeneic GVHD recipient animals were sacrificed. Spleens, and inguinal and mesenteric lymph nodes, as well as the small bowel were removed and frozen in liquid nitrogen or fixed in $10 \%$ phosphate buffered formalin ( $\mathrm{pH}$ 7.4) pending further analysis. Control animals consisted of irradiated $\mathrm{B} 6 \mathrm{D} 2 \mathrm{~F} 1$ mice which received the same amount of syngeneic (B6D2F1) cells.

In a further subset of experiments lymphocytes of gld/gld (FasL deficient) mice on a C57BL/6 genetic background (Charles River, Sulzield, Germany) were prepared and transferred into $\mathrm{B} 6 \mathrm{D} 2 \mathrm{~F} 1$ recipient mice as stated above. Mice were sacrificed on day 3 to study apoptosis and on days 3 and 6 to investigate mucosal atrophy.

TREATMENT REGIMENS OF RECIPIENT ANIMALS After induction of GVHD one group of recipient B6D2F1 mice was treated with a neutralising anti-TNF- $\alpha$ antibody (Pharmingen, San Diego, California, USA; $200 \mu \mathrm{g} /$ day intraperitoneally), a rabbit polyclonal anti-FasL antibody (200 $\mu \mathrm{g} /$ day intraperitoneally), a known neutralising monoclonal hamster anti-FasL antibody (MFL-3, Pharmingen), or pentoxifylline (Albert-Roussel, Wiesbaden, Germany; $100 \mathrm{mg} / \mathrm{kg}$ bodyweight twice a day, intraperitoneally). The animals were sacrificed at day 3 or day 6 , respectively, and organs were removed as described above.

The polyclonal anti-FasL antibody was raised in rabbits after immunisation with a KLH linked peptide of the extracellular domain of the murine Fas-L molecule ${ }^{11}$ (aa 200-214: CNNQPLNHKVYMRNS). The antibody was affinity purified using peptide coated Sepharose (Pharmacia, Uppsala, Sweden) as described previously. ${ }^{12}$

The efficacy of the monoclonal hamster anti-FasL (MFL-3) antibody in blocking apoptosis in vitro has been shown by Kayagaki et $a l .{ }^{13}$ To test the efficacy of rabbit polyclonal anti-FasL antibody, the following in vitro assay was performed: murine splenic $\mathrm{T}$ cells were prepared and stimulated on anti-CD3 coated six well plates for 48 hours. The supernatant was then removed and the cells transferred to a novel, anti-CD3 coated six well plate. Apoptosis under these conditions (interleukin 2 (IL-2) withdrawal during restimulation) is known to be caused by the FasL-Fas interaction. ${ }^{14}$ Some of the cells were incubated in the presence of polyclonal anti-FasL antibody $(10 \mu \mathrm{g} / \mathrm{ml})$. Six hours later cytospins of these cells were made. Apoptosis was detected using the ApopTag in situ apoptosis detection kit (Oncor, Gaithersburg, Pennsylvania, USA).

DETECTION OF MUCOSAL ATROPHY

Formalin fixed jejunum specimens were embedded in paraffin wax and cut into $6-8 \mu \mathrm{m}$ sections. To detect mucosal atrophy and crypt hyperplasia slides were stained with haematoxylin and eosin and the villous height and crypt depth were measured using a graded ocular.

DETECTION OF APOPTOTIC CELLS

In order to determine the rate of apoptosis during acute GVHD, treated and untreated recipient animals were sacrificed at various time points (one to six days) after induction of GVHD; the jejunum was removed and snap frozen in liquid nitrogen. To detect apoptotic cells with the help of the TUNEL technique the ApopTag in situ apoptosis detection kit (Oncor) was used according to the manufacturer's instructions.

\section{MIXED LYMPHOCYTE REACTION}

To investigate whether treatment with pentoxifylline leads to a generalised downregulation of the immune response of the C57BL/6 donor lymphocyte against the allogeneic stimulus or whether it only affects TNF- $\alpha$ mediated mechanisms, splenic lymphocytes of syngeneic control animals, GvH animals, and pentoxifylline treated $\mathrm{GvH}$ animals were prepared and cocultured with irradiated (3 Gy) DBA2 splenocytes. After 72 hours proliferation was assessed using ${ }^{3} \mathrm{H}$-thymidine as described elsewhere. ${ }^{15}$ Interferon $\gamma$ (IFN- $\left.\gamma\right)$ was measured in the supernatants using a sandwich ELISA technique provided by Pharmingen.

\section{Results}

HISTOLOGICAL CHANGES IN THE JEJUNUM AFTER INDUCTION OF ACUTE GVHD

In accordance with earlier reports, ${ }^{10}{ }^{16}$ two to three days after induction of GVHD the lamina propria and the mucosal epithelium began to be infiltrated by increased numbers of CD4+ and CD8+ T cells. ${ }^{4}$ At that time the villi began to appear atrophic and the crypt depths increased. The animals appeared grossly healthy until about one week after induction of acute GVHD. Later the animals developed diarrhoea, weight loss, and skin changes. Most of the animals died between days 14 and 21 after lymphocyte transfer. Histological changes in the jejunum were assessed on day 6 , when the animals still appeared healthy.

Irradiated (7.5 Gy) control animals that received syngeneic lymphocytes did not show a significant change in mucosal architecture at day 6 compared with totally untreated animals (data not shown). This result is in accordance 

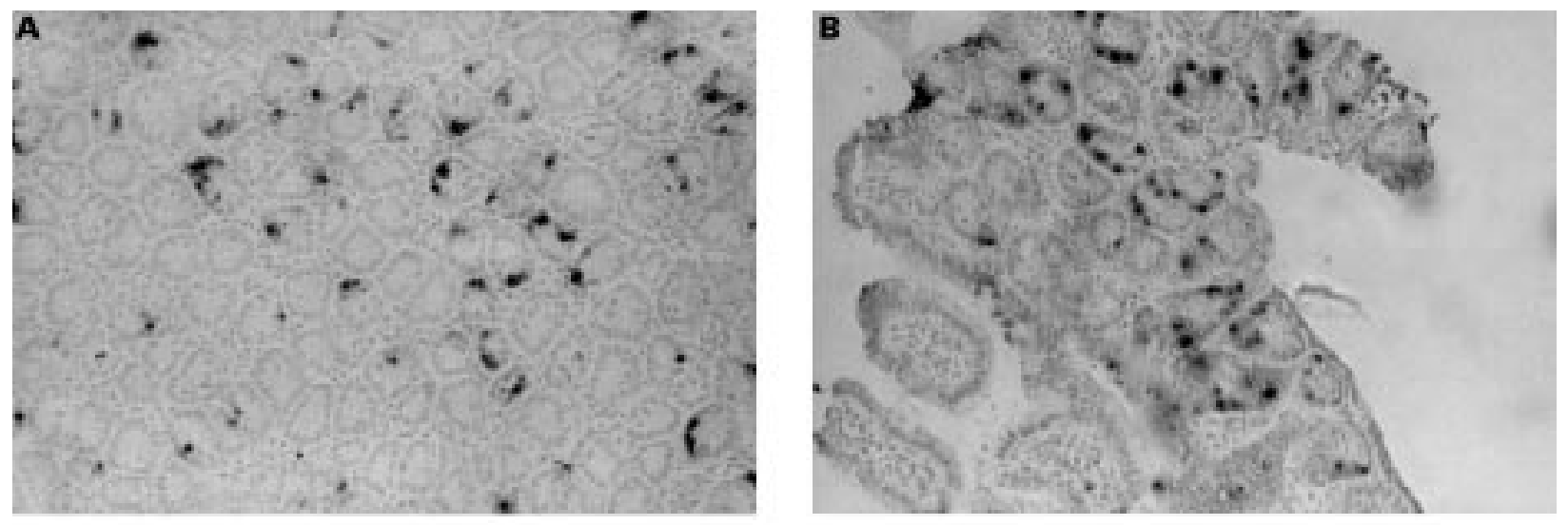

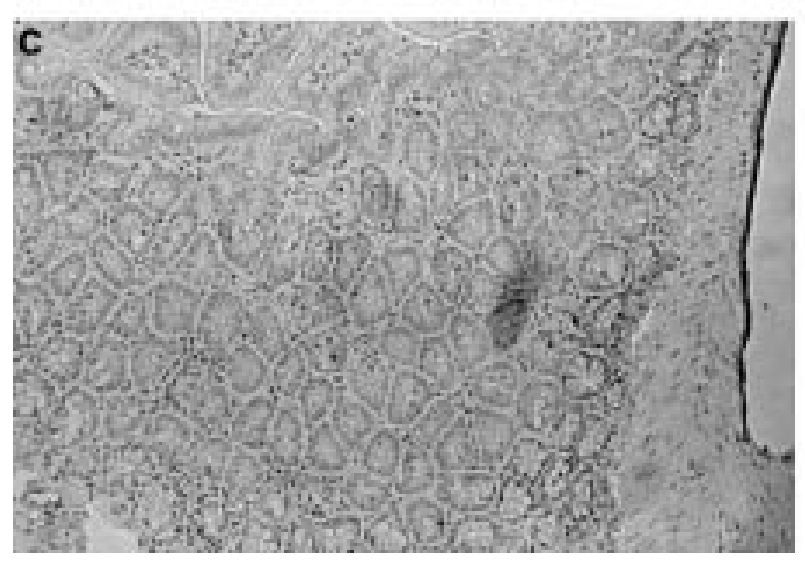

with earlier studies by Potten et $a l,{ }^{17}$ who proved that irradiation at the dosage chosen does not lead to lasting damage of the intestinal mucosa.

RATE OF EPITHELIAL CELL APOPTOSIS

Previously, we have shown that villous atrophy in the $\mathrm{GvH}$ animals is preceded by programmed epithelial cell death (apoptosis), ${ }^{4}$ as has been speculated before. ${ }^{18}$ However, it is not known which of the two most investigated mediators of apoptosis (Fas and TNF- $\alpha$ ) is mainly responsible for induction of apoptosis in this animal model. Therefore, we treated the animals undergoing acute $\mathrm{GvH}$ reaction with neutralising anti-TNF- $\alpha$ or two different antiFasL antibodies, respectively, for three days and counted the number of apoptotic cells in the epithelial cell layer using the TUNEL technique at day 3 after induction of acute GVHD. As shown in fig 1 , apoptosis is significantly inhibited by administration of neutralising anti-TNF- $\alpha$ antibody but not by the neutralising anti-FasL antibodies, indicating that the FasL-Fas system is probably not as important for induction of intestinal apoptosis in murine

Table 1 Number of apoptotic cells in each group

\begin{tabular}{ll}
\hline & Apoptotic cells/HPF \\
\hline Syngeneic control & $1.1(0.5)$ \\
GVHD & $35(7)$ \\
GVHD + anti-TNF- $\alpha$ & $1(1)$ \\
GVHD + anti-FasL & $34(10)$ \\
\hline
\end{tabular}

Apoptotic cells were counted in 10-15 well oriented sections per animal. Data are expressed as number (SD) of apoptotic cells per high power field (HPF).

GVHD, graft versus host disease; TNF, tumour necrosis factor. acute $\mathrm{GvH}$ as is TNF- $\alpha$. Table 1 shows the exact numbers of apoptotic cells. Furthermore, treatment with anti-FasL antibodies did not inhibit mucosal transformation in the acute $\mathrm{GvH}$ reaction (data not shown).
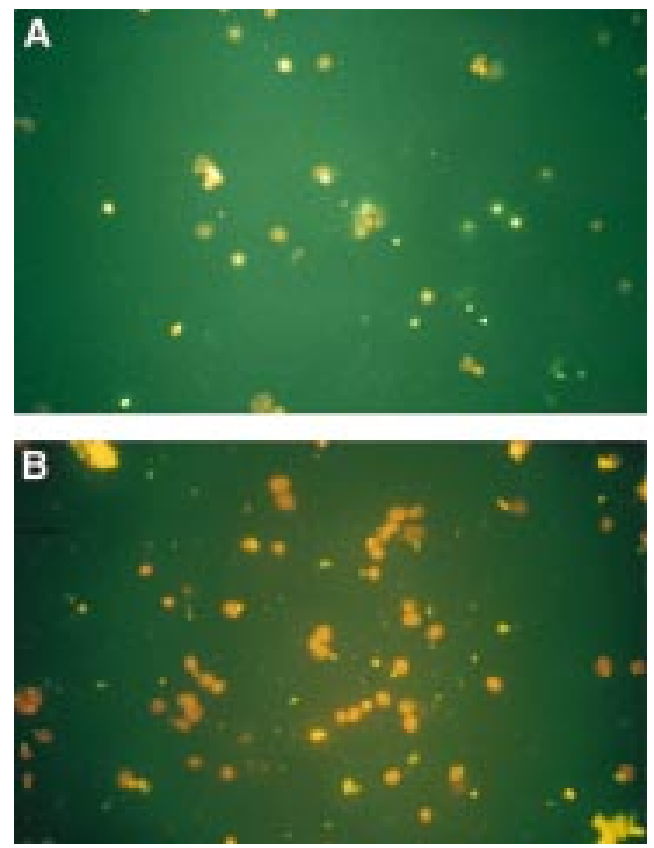

Figure 2 (A) Cytospins of T cells without FasL antibody; (B) cytospins of $T$ cells in the presence of polyclonal anti-FasL antibody. Slides were stained with the

fluorescence ApopTag direct apoptosis in situ detection kit and counterstained with propidium iodide. Data represent results of two different experiments. 
Table 2 Effect of pentoxifylline $(P F)$ treatment

\begin{tabular}{lllll}
\hline & $\begin{array}{l}\text { Villous length } \\
(\mu \mathrm{m})\end{array}$ & $\begin{array}{l}\text { Crypt depth } \\
(\mu \mathrm{m})\end{array}$ & $\begin{array}{l}\text { Crypt:villous } \\
\text { ratio }\end{array}$ & $\begin{array}{l}\text { Apoptotic } \\
\text { cells/HPF }\end{array}$ \\
\hline Syngeneic control & $310(29)$ & $94(9)$ & 0.31 & $1.1(0.5)$ \\
GVHD & $198(21)$ & $176(11)$ & 0.88 & $35(7)$ \\
GVHD + PF & $279(25)$ & $109(15)$ & 0.37 & $2.3(2)$ \\
\hline
\end{tabular}

Villous length and crypth depth were measured after six days by a graded ocular in at least 10 complete, 10 semiallogenic untreated, and six pentoxifylline treated animals. Data represent the average (SD) of these measurements.

$\mathrm{HPF}$, high power field; GVHD, graft versus host disease.

Figure 2 shows the efficacy of the polyclonal anti-FasL antibody in preventing apoptosis in vitro. In the presence of the polyclonal anti-FasL antibody approximately $5-10 \%$ of the visible cells underwent apoptosis; without this antibody $30-50 \%$ of the cells were apoptotic (fig $2 \mathrm{~A}$ ).

INDUCTION OF APOPTOSIS, VILLOUS ATROPHY, AND CRYPT HYPERPLASIA BY FasL DEFICIENT DONOR CELLS

As described by Takahashi et al, ${ }^{11}$ the lymphoproliferative disease observed in gld mice is caused by a point mutation in the FasL gene on chromosome 1, resulting in expression of a non-functional FasL protein. The expressed FasL does not induce apoptosis. Therefore, we tested our hypothesis that the FasL-Fas interaction might not be important for induction of crypt cell apoptosis in murine acute semiallogeneic GVHD by using donor lymphocytes of gld mice on a BL/6 genetic background. As shown in fig 3, the FasL deficient donor cells still induce apoptosis (24 (10) apoptotic cells per high power field) and
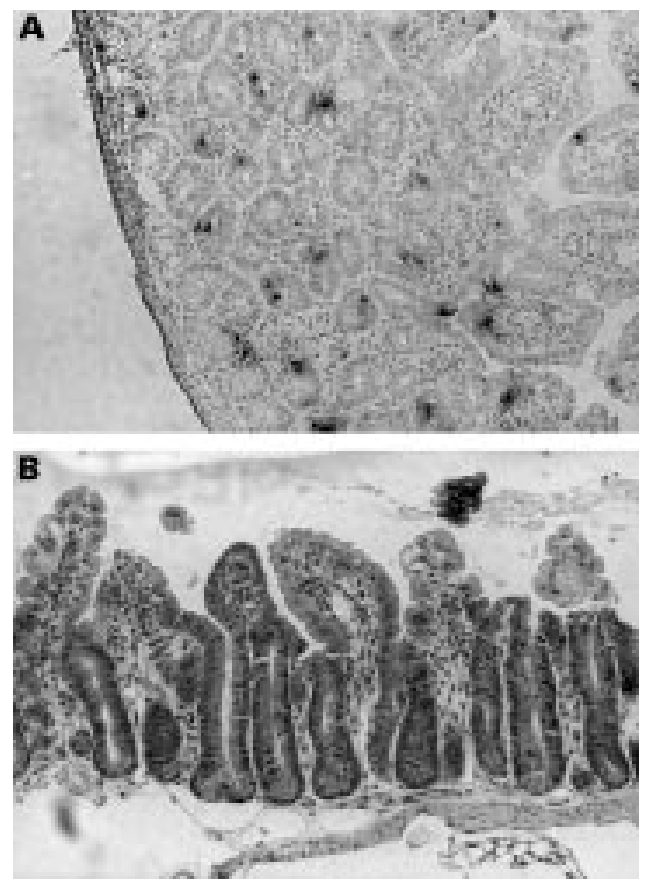

Figure 3 Irradiated $B 6 D 2 F 1$ mice received gld/gld lymphocytes and were sacrificed on day 3 to detect apoptotic cells using the TUNEL technique $(A ; n=4)$; paraffin wax sections of the jejunum were prepared and stained with haematoxylin and eosin $(B ; n=4)$. These photomicrographs clearly show ongoing apoptosis in the jejunal crypt epithelium and the manifestation of crypt hyperplasia and villous atrophy.

profound villous atrophy and crypt hyperplasia (villous length $174(12.5) \mu \mathrm{m}$, crypt depth 159 (14) $\mu \mathrm{m}$, crypt/villous ratio $0.91, \mathrm{n}=4$ ). This
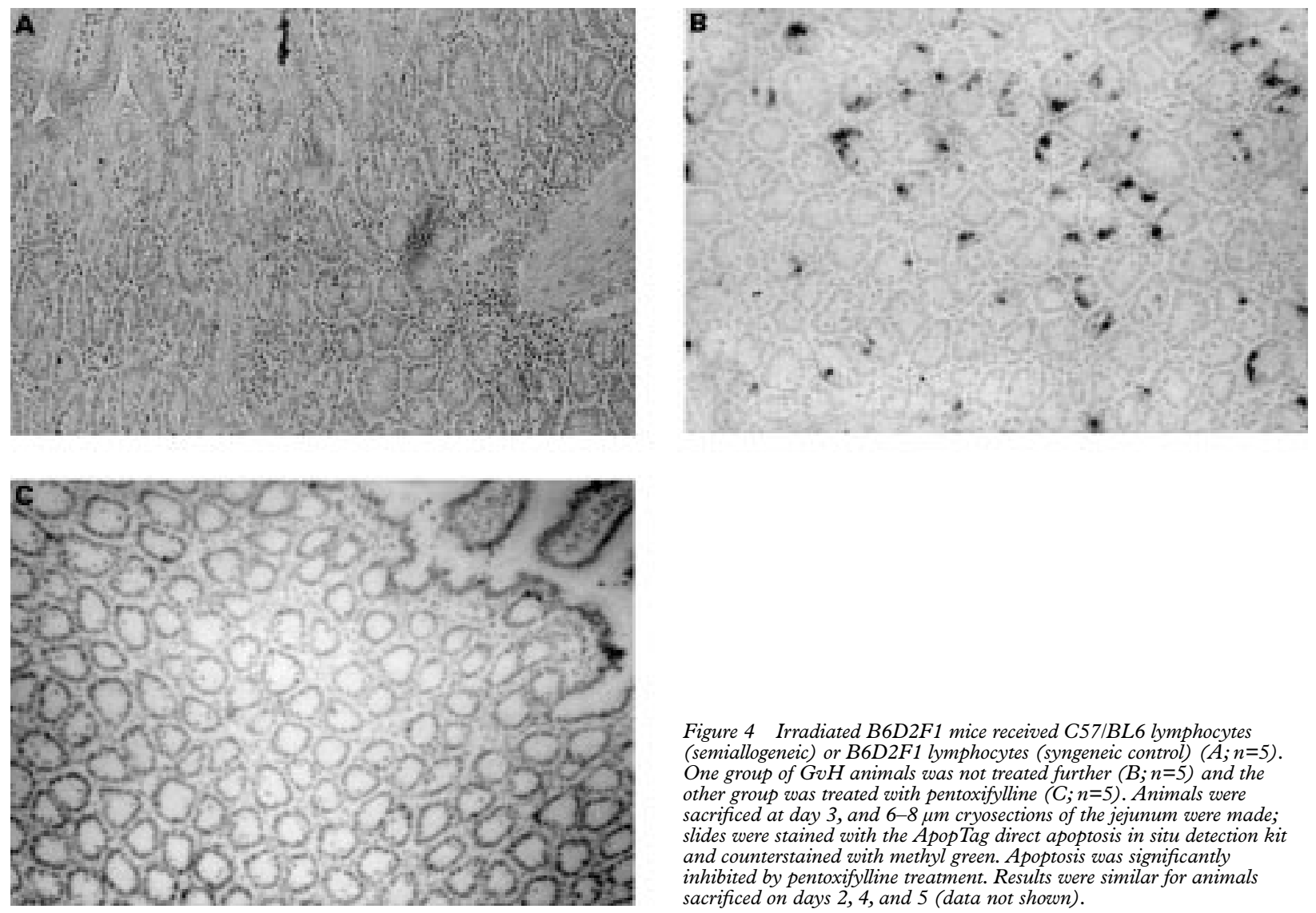

Figure 4 Irradiated B6D2F1 mice received C57/BL6 lymphocytes (semiallogeneic) or B6D2F1 lymphocytes (syngeneic control) $(A ; n=5)$. One group of $G v H$ animals was not treated further $(B ; n=5)$ and the other group was treated with pentoxifylline $(C ; n=5)$. Animals were sacrificed at day 3, and 6-8 $\mu \mathrm{m}$ cryosections of the jejunum were made; slides were stained with the Apop Tag direct apoptosis in situ detection kit and counterstained with methyl green. Apoptosis was significantly inhibited by pentoxifylline treatment. Results were similar for animals sacrificed on days 2, 4, and 5 (data not shown). 

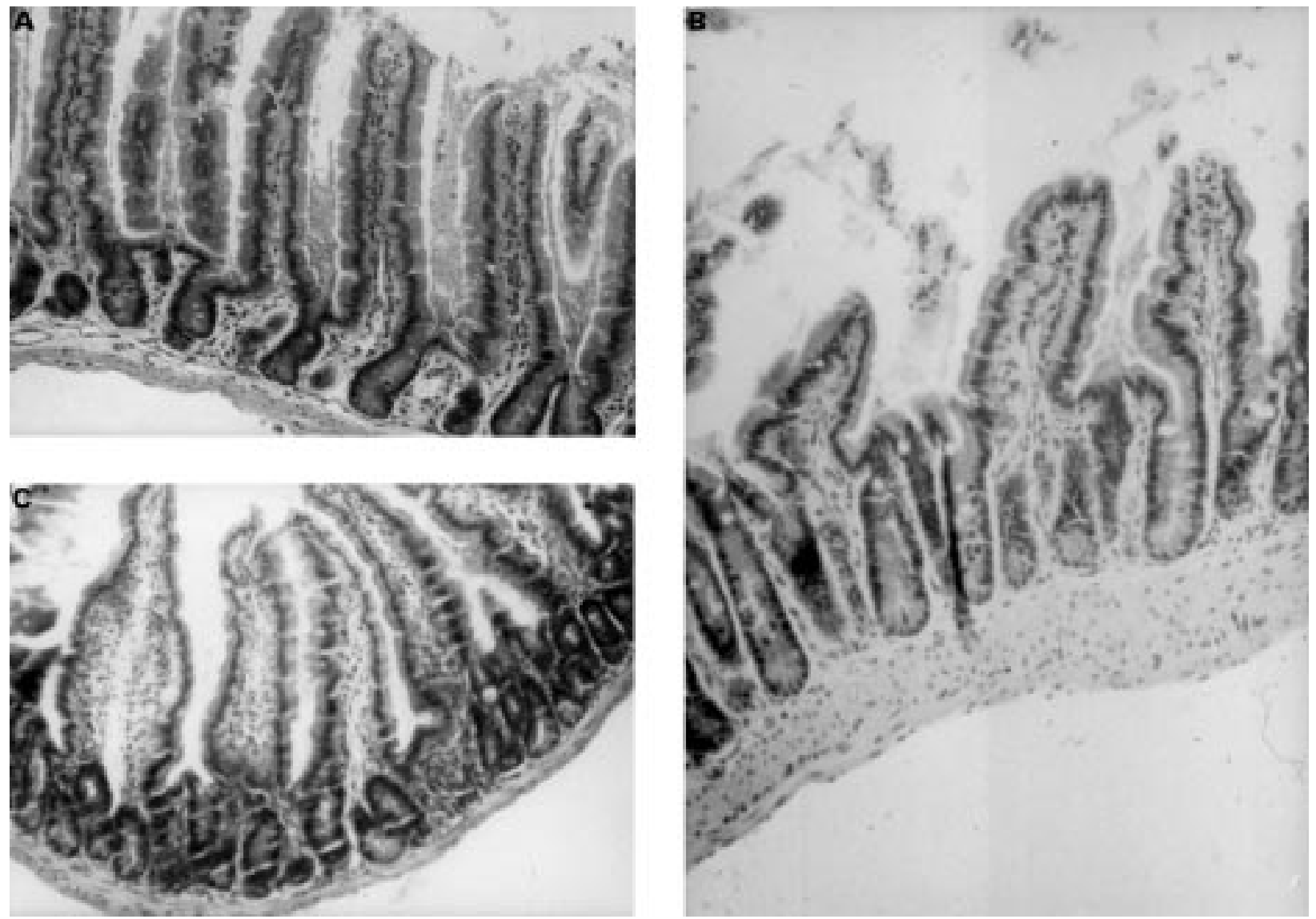

Figure 5 Irradiated B6D2F1 mice received C57/BL6 lymphocytes (semiallogeneic) or B6D2F1 lymphocytes (syngeneic control) $(A ; n=5)$. One group of $G v H$ animals was not treated further $(B ; n=5)$ and the other group was treated with pentoxifylline $(C ; n=5)$. Animals were sacrificed at day 6 , the jejunum was removed and fixed in 10\% phosphate buffered formalin. After being embedded in paraffin wax, 6-8 $\mathrm{mm}$ sections were cut and the slides were stained with haematoxylin and eosin. The mucosal architecture was almost normalised after the application of pentoxifylline.

finding thus corroborates results of studies using the two different anti-FasL antibodies as shown above.

EFFECT OF PENTOXIFYLLINE ON APOPTOSIS, INTESTINAL MORPHOLOGY, AND ALLOGENEIC LYMPHOCYTE ACTIVATION

Other investigators ${ }^{7}$ have shown that treatment of mice undergoing acute $\mathrm{GvH}$ with antiTNF- $\alpha$ leads to an inhibition of the development of mucosal atrophy, emphasising the important role of apoptosis in the intestinal manifestation of GVHD. Thus, we wondered whether pentoxifylline, a known inhibitor of TNF- $\alpha$ release in vivo and in vitro, ${ }^{9}$ would bring about normalisation of intestinal morphology. Therefore, we treated some animals after the induction of acute $\mathrm{GvH}$ with pentoxifylline. This treatment led to a profound inhibition of apoptosis (fig 4) and also of the degree of the lymphocytic infiltrate, crypt hyperplasia, and villous atrophy, as shown in fig 5. The ratio of crypt depth to villous length was almost normalised (from 0.88 in $\mathrm{GvH}$ animals

Table 3 Proliferation and interferon (IFN) $\gamma$ secretion

\begin{tabular}{lll}
\hline & Proliferation (cpm) & IFN- $\gamma(\mathrm{ng} / \mathrm{ml})$ \\
\hline GVHD (untreated) & 4224 & 8.3 \\
Syngeneic control & 391 & $<0.3$ \\
GVHD + pentoxifylline & 4412 & 7.1
\end{tabular}

Data represent one of three similar experiments.

GVHD, graft versus host disease. to 0.37 in pentoxifylline treated animals). Syngeneic control animals had a crypt: villous ratio of 0.29 (table 2).

When a mixed lymphocyte reaction was performed using in vivo activated lymphocytes of treated (pentoxifylline) and untreated $\mathrm{GvH}$ animals, no difference in the rate of proliferation on restimulation and in the secretion of IFN- $\gamma$ could be found (table 3 ), indicating that complete allogeneic stimulation was not abolished by application of pentoxifylline.

\section{Discussion}

Murine acute GVHD has long been investigated for two reasons: as an animal model for the immune pathomechanisms of human GVHD after allogeneic bone marrow transplantation. Furthermore, due to its characteristic changes in the intestinal histology consisting of lymphocytic infiltrates, crypt hyperplasia, and villous atrophy, it serves as a model for immunologically mediated atrophichyperregenerative diseases of the intestine (for example, coeliac disease, Whipple's disease, bacterial overgrowth). ${ }^{19}$ The systemic cytokine profile associated with the above mentioned changes in the intestinal architecture has been determined to be dominated by a Th1 pattern (predominance of IFN- $\gamma$ secretion). ${ }^{20}$ Neutralising antibodies to IFN- $\gamma$ and to IL-12, which governs Th1 differentiation, ${ }^{21}$ can abolish the systemic manifestation of acute murine 
$\mathrm{GvH} .{ }^{22-24}$ Inflammatory cyokines such as TNF- $\alpha$ were also shown to be involved in development of these intestinal alterations in this animal model. ${ }^{7}$ These cytokine studies are paralleled by investigations of human biopsy material of patients with coeliac disease, which show similar cytokine expression patterns to those seen in murine acute GVHD. ${ }^{25-27}$ How the investigated cytokines regulate epithelial growth, damage, and regeneration is still a matter of debate. However, it has been shown that TNF- $\alpha$ and IFN- $\gamma$ can induce upregulation of MHC class II molecules in epithelial cells and thereby indirectly render them a better target for cytotoxic $\mathrm{T}$ cells. ${ }^{19}$ Furthermore, it has also been speculated that these cytokines exert directly damaging effects on the gastrointestinal mucosa. ${ }^{6728}$ In a previous study we showed that apoptosis of crypt epithelial cells occurs during the process of mucosal transformation in acute murine $\mathrm{GvH} .{ }^{4}$ Again, this finding is paralleled in a study by Moss et $a{ }^{29}$, who found increased epithelial cell apoptosis in duodenal biopsy specimens of patients with coeliac disease. In contrast to our studies, they showed enhanced apoptosis in the villous tip area and not in the crypt epithelium. Furthermore, a recent study by Guy-Grand et al showed increased villous cell apoptosis in TNF- $\alpha$ treated normal animals, ${ }^{30}$ thus corroborating the importance of TNF- $\alpha$ in intestinal apoptosis, as was found in the present study. However, the systemic application of high concentrations of this cytokine does not mimic any known pathophysiological condition (neither $\mathrm{GvH}$ reaction nor coeliac disease). Therefore, the difference in the location in which apoptosis occurs might result from the chosen experimental setting.

In the present study we investigated the mechanism of the induction of epithelial cell apoptosis in acute murine GVHD. We focused on the two most investigated mediators of apoptosis: TNF- $\alpha$ and the FasL-Fas interaction. Using neutralising antibodies, we found that $\mathrm{TNF}-\alpha$ - either directly or indirectly-is most likely responsible for the induction of apoptosis in the acute $\mathrm{GvH}$ reaction. The latter finding is corroborated by studies using gld (FasL deficient) mice, showing that even in the absence of a functional FasL-Fas interaction apoptosis, crypt hyperplasia, and villous atrophy do occur in this animal model. However, these results are in contrast to the conclusion of the study by Sakai et al, in which they showed the capacity of freshly prepared intraepithelial lymphocytes of $\mathrm{GvH}$ animals to cause cytotoxicity in vitro via a FasL mediated mechanism. ${ }^{8}$ However, in their experimental setting the recipient mice were not irradiated. Unirradiated mice develop only insignificant mucosal atrophy (personal observation). Therefore, the in vivo relevance of the FasL-Fas interaction could not be investigated. With reference to our data using the neutralising anti-FasL antibodies we would speculate that the FasL-Fas interaction might have only a minor effect on the manifestation of epithelial apoptosis and villous atrophy in vivo. It is possible that other newly discovered factors-such as TRAIL $^{31}$ and TRAMP 32 -may also influence this process. This should be investigated in future studies.

The source of TNF- $\alpha$ in acute $\mathrm{GvH}$ is not known. It has been shown that $\mathrm{T}$ cells and macrophages produce increased amounts of this inflammatory cytokine, especially in later phases of established GVHD. ${ }^{20} 33$ Surprisingly, it has been shown by in situ hybridisation techniques that in normal human and murine intestine Paneth cells are the major source of TNF- $\alpha .^{34}{ }^{35}$ Thus, it is possible that in the initial phase of murine acute $\mathrm{GvH}$ the Paneth cells are either destroyed and thereby release $\mathrm{TNF}-\alpha$ or are somehow stimulated to secrete TNF- $\alpha$. Later, $\mathrm{T}$ cells and macrophages may be the source of this cytokine. This hypothesis may also explain the above stated difference in localisation of the apoptotic cells in the mouse model and in human coeliac disease. To test this theory, we are currently investigating the effects of the manifestation of acute $\mathrm{GvH}$ on Paneth cells.

Having found that TNF- $\alpha$ is crucial for crypt cell apoptosis in murine GVHD, we wanted to test the efficacy of the phosphodiesterase inhibitor pentoxifylline, a clinically well known substance that inhibits $\mathrm{TNF}-\alpha$ secretion by many cell types both in vitro and in vivo. ${ }^{9} \mathrm{We}$ found that pentoxifylline-although it does not completely downregulate allogeneic $\mathrm{T}$ cell stimulation-abolished TNF mediated apoptosis of the crypt cells and reduced the occurrence of crypt hyperplasia and villous atrophy after induction of the acute $\mathrm{GvH}$ reaction. Thus, it is possible that patients with immune mediated villous atrophy and crypt hyperplasia, that do not respond to standard treatments, could benefit from treatment with pentoxifylline, a substance with few side effects. ${ }^{9}$ This treatment would be more cost efficient compared with treatment with an antibody against human $\mathrm{TNF}-\alpha$, which should theoretically also be effective in reducing mucosal atrophy. In addition, pentoxifylline has been shown to prevent experimental encephalomyelitis in rats by selectively suppressing Th1 cytokines, ${ }^{36}{ }^{37}$ thus making this substance even more interesting for the treatment of immune mediated diseases.

The molecular mechanism of pentoxifylline has been shown by a recent study which identified its selective inhibitory effect on the transcription factor c-Rel in activated T cells. ${ }^{38}$ In contrast to cyclosporin A and FK506 other transcription factors such as NF-AT are not influenced, making pentoxifylline much more selective than these two immunosuppressants. In in vitro experiments ${ }^{39}$ and also in animal and human studies, the striking inhibitory effect on $\mathrm{TNF}-\alpha$, but not IL- 6 production in various models of endotoxaemia induced TNF release was often shown. ${ }^{40}$ However, when pentoxifylline was tested outside a laboratory setting-for example, in the treatment of $\mathrm{GvH}$ after bone marrow transplantation or of Gram negative sepsis, two diseases in which TNF- $\alpha$ is thought to play a crucial, fatal role, the outcome was rather disappointing. ${ }^{41}{ }^{42}$ Possibly, the effect of pentoxifylline is too selective and does not 
influence other unknown pathomechanisms besides TNF- $\alpha$. Therefore, its clinical impact in treatment of diseases other than claudicatio intermittens is limited.

In conclusion, we have shown that $\mathrm{TNF}-\alpha-$ and not the FasL-Fas interaction-is (directly or indirectly) mainly responsible for induction of epithelial apoptosis in the acute murine $\mathrm{GvH}$ reaction. Treatment with pentoxifylline, a known inhibitor of TNF- $\alpha$ production, results in a decreased rate of crypt cell apoptosis and inhibition of the occurrence of crypt hyperplasia and villous atrophy in this animal model, suggesting a possible clinical application of this substance in patients with immune mediated villous atrophy and crypt hyperplasia.

We acknowledge the superb technical assistance of Maren Dirks. The study was supported by a grant of the Deutsche Forschungsgemeinschaft (STU 157/3-1).

1 Sanders EJ, Wride MA. Programmed cell death in development. Int Rev Cytol 1995;163:105-73.

2 Liebermann DA, Hoffman B, Steinman RA. Molecular controls of growth arrest and apoptosis: p53-dependent and independent pathways. Oncogene 1995;11:199-210.

3 Allen PD, Bustin SA, Macey MG, et al. Programmed cell death (apoptosis) in immuity and haematological neoplasia. Br f Biomed Sci 1993;50:135-49.

4 Stüber E, v Freier A, Marinescu D, et al. Involvement of OX40-OX40L interactions in the intestinal manifestations of murine acute graft-versus-host disease. Gastroenterology 1998;115:1205-15.

5 Vaux DL, Strasser A. The molecular biology of apoptosis. Proc Natl Acad Sci USA 1996;93:2239-44

6 Garside P, Bunce C, Tomlinson C, et al. Analysis of enteropathy induced by tumour necorsis factor $a$. Cytokine 1993;5:24-30.

7 Piguet PF, Grau GE, Allet B, et al. Tumor necrosis factor/cachectin is an effector of skin and gut lesions of the factor/cachectin is an effector of skin and gut lesions of the

8 Sakai T, Kimura Y, Inagaki-Ohara K, et al. Fas-mediated cytotoxicity by intestinal intraepithelial lymphocytes during acute graft-versus-host disease in mice. Gastroenterology 1997;113:168-74

9 Zabel P, Schade FU, Schlaak M. Pentoxifyllin-eine Synthesehemmer für Tumor-Nekrose-Faktor-alpha. Immun Infekt 1992;20:80-3.

10 Guy-Grand D, Vassalli P. Gut injury in mouse graft-versushost reaction. $\mathcal{F}$ Clin Invest 1986;77:1584-95.

11 Takahashi T, Tanaka M, Brannan CI, et al. Generalized lymphoproliferative disease in mice, caused by a poin mutation in the Fas ligand. Cell 1994;76:969-76.

12 Stüber E, Strober W. The T cell-B cell interaction via OX40-OX40L is necessary for the $\mathrm{T}$ cell dependent humoral immune response. f Exp Med 1996;183:979-90.

13 Kayagaki N, Yamaguchi N, Nagao F, et al. Polymorphism of murine Fas ligand that affects the biological activity. Proc Natl Acad Sci USA 1997;94:3914-19.

14 Boussiotis VA, Lee BJ, Freeman GJ, et al. Induction of T cell clonal energy results in resistance, whereas CD28clonal energy results in resistance, whereas CD28-
mediated costimulation primes for susceptibility to Fasand Bax-mediated programmed cell death. F Immunol and Bax-mediated

15 Stüber ER, Neurath MF, Calderhead D, et al. Crosslinking of OX40-ligand, a member of the NGF/TNF family of cytokines, induces proliferation and differentiation in murine splenic B cells. Immunity 1995;2:507-21

16 Tsuzuki T, Yoshibai Y, Ito $M$, et al. Kinetics of intestinal intraepithelial lymphocytes during acute graft-versus-host disease in mice. Eur f Immunol 1994;24:709-15.

17 Potten CS. Regeneration in epithelial proliferative units as exemplified by small intestinal crypts. Ciba Foundation Symposium 1991;161:54-76.

18 Suzuki M, Suzuki Y, Ikeda H, et al. Apoptosis of murine large intestine in acute graft-versus-host disease after allogeneic bone marrow transplantation across minor histogeneic bone marrow transplantation across minor histo-
19 Marsh MN. Gluten, major histocompatibility complex, and the small intestine. Gastroenterology 1992;102:330-54.

20 Garside P, Reid S, Steel M, et al. Differential cytokine production associated with distinct phases of murine graftversus-host reaction. Immunology 1994;82:211-14.

21 Trinchieri G. Interleukin-12: a proinflammatory cytokine with immunoregulatory functions that bridge innate resistance and antigen-specific adaptive immunity. Anпu Rev Immunol 1995;13:251-76.

22 Mowat AM. Antibodies to IFN- $\gamma$ prevent immunologically mediated intestinal damage in murine graft-versus-host reaction. Immunology 1989;68:18-23.

23 Williamson E, Garside P, Bradley JA, et al. Neutralizing IL-12 during induction of murine acute graft-versus-host disease polarizes the cytokine profile toward a Th2-type alloimmue response and confers long term protection from disease. F Immunol 1997;159:1208-15.

24 Williamson E, Garside P, Bradley JA, et al. IL-12 is a central mediator of acute graft-versus-host disease in mice. $\mathcal{F}$ Immunol 1996;157:689-99.

25 Dawoud AA, Nakshabendi I, Foulis A, et al. Immunohistochemical analysis of mucosal gamma-interferon production in coeliac disease. Gut 1992;33:1482-6.

26 Breese EJ, Kumar P, Farthing MJ, et al. Interleukin-2 and interferon- $\gamma$ producing cells in the lamina propria in coeliac disease. Dig Dis Sci 1994;39:2243.

27 Nilsen EM, Lundin KEA, Krajci P, et al. Gluten specific, HLA-DQ restricted $\mathrm{T}$ cells from coeliac mucosa produce cytokines with Th1 or Th0 profile dominated by interferon $\gamma$. Gut 1995;37:766-76.

28 Przemioslo RT, Lundin KEA, Sollid LM, et al. Histological changes in small bowel mucosa induced by gliadin sensitive T lymphocytes can be blocked by anti-interferon $\gamma$ antibody. Gut 1995;36:874-9.

29 Moss SF, Attia L, Scholes JV, et al. Increased small intestinal apoptosis in coeliac disease. Gut 1996;39:811-17.

30 Guy-Gran D, DiSanto JP, Henchoz P, et al. Small bowel enteropathy: role of intraepithelial lymphocytes and of cytokines (IL-12, IFN- $\gamma$, TNF) in the induction of epithelial cell death and renewal. Eur f Immunol 1998;28:730-44.

31 Wiley SR, Schooley K, Smolak PJ, et al. Identification and characterization of a new member of the TNF family that induces apoptosis. Immunity 1995;3:673-82.

32 Bodmer JL, Burns K, Schneider P, et al. TRAMP, a novel apoptosis-mediating receptor with sequence homology to tumor necrosis factor receptor 1 and Fas (Apo-1, CD95). Immunity 1997;6:79-88.

33 Nestel FP, Price KS, Seemayer TA, et al. Macrophage priming and lipopolysaccharide-triggered release of tumor necrosis factor $\alpha$ during graft-versus-host disease. 7 Exp Med 1992;175:405-13.

34 Tan X, Hsueh W, Gonzalez-Crussi F. Cellular localization of tumor necrosis factor (TNF)-alpha transcripts in normal bowel and in necrotizing enterocolitis. TNF gene expression by Paneth cells, intestinal eosinophils and macrophages. Am f Pathol 1993;142:1858-65.

35 Keshav S, Lawson L, Chung LP, et al. Tumor necrosis factor mRNA localized to Paneth cells of normal murine intestinal epithelium by in situ hybridization. 7 Exp Med 1990;171:327-32

36 Rott O, Cash E, Fleischer B. Phosphodiesterase inhibitor pentoxifylline, a selective suppressor of T helper type 1- but not type 2-associated lymphokine production, prevents induction of experimental autoimmune encephalomyelitis in Lewis rats. Eur F Immunol 1993;23:1745-51.

37 Okuda Y, Sakoda S, Fujimura H, et al. Pentoxifylline delays the onset of experimental allergic encephalomyelitis in mice by modulating cytokine production in peripheral blood mononuclear cells. Immunopharmacology 1996;35: $141-8$.

38 Wang W, Tam WF, Hughes CCW, et al. c-Rel is a target of pentoxifylline-mediated inhibition of T lymphocyte activapentoxifylline-mediated inhibition

39 Tilg H, Eibl B, Pichl M, et al. Immune response modulation by pentoxifylline in vitro. Transplantation 1993;56:196-201

40 Waage A, Sorensen M, Stordahl B. Differential effect of oxpentifylline on tumour necrosis factor and interleukin-6 production. Lancet 1990;335:543.

41 Attal M, Huguet F, Rubie $\mathrm{H}$, et al. Prevention of regimen-related toxicities after bone marrow transplantation by pentoxifylline: a prospective, randomized trial. Blood 1993;82:732-6.

42 Clift RA, Bianco JA, Appelbaum FR, et al. A randomized controlled trial of pentoxifylline for the prevention of regimen-related toxicities in patients undergoing allogeneic marrow transplantation. Blood 1993;82:2025-30. 